\title{
Влияние различной температуры и влажности при инкубации перепелиных яиц породы радонежские от матерей разного возраста на развитие эмбрионов
}

Долгорукова А.М., кандидат биологических наук, ведущий научный сотрудник

Зотов А.А., кандидат сельскохозяйственных наук, ведущий научный сотрудник

Тишенкова М.С., научный сотрудник

Данилов Р.В., главный специалист

Мелехина Т.А., главный специалист

ФГБНУ Федеральный научный центр «Всероссийский научно-исследовательский и технологический институт птицеводства» РАН (ФНЦ «ВНИТИП» РАН)

\begin{abstract}
Аннотация: В исследовании сравнивали результаты инкубации яии нобой породы мясных перепелов радонежские 1 1-, 22- и 35-недельного бозраста с использованием разных режимов инкубации. Показано, что с возрастом матерей снижались оплодотворенность яии и вывод перепелят, тогда как выводимость яии, была самой низкой у матерей 22-недельного бозраста. В группах с дифререниированным режимом инкубации быбодимость яии, была быше, чем 6 контрольных группах со стабильным режимом инкубации, на 2,6-9,3\%, разница была достоверной у молодых перепелов ( $p<0,01)$. Вызод перепелят из яии от $11-и$ 35-недельных матерей был быше в группах с дифференцированным режимом инкубации по сравнению с контрольными группами $(p<0,05)$.
\end{abstract}

ключебые слова: перепела породы радонежские, качество инкубационных яии, бозраст матерей, температура и блажность инкубации, оплодотворенность яии, быводимость яии, бывод перепелят.

Введение. Существует множество факторов, влияющих на эмбриональное развитие на протяжении всего периода инкубации, включая температуру окружающей среды, влажность, движение воздуха и поворот яиц. Эти факторы меняются в зависимости от количества заложенных яиц, возраста яиц при закладке, возраста и видовой принадлежности матерей [1]. Известно, что с возрастом матерей меняются морфологические и биохимические признаки яиц, что было показано как на курах [2], так и на перепелах [3]. Так, с возрастом кур мясного направления продуктивности меняется соотноше- ние основных частей яйца - желтка и белка, масса яиц увеличивается, а относительная масса скорлупы снижается [4].

Однако следует отметить, что влияние возраста самок перепелов на качество яиц значительно слабее по сравнению с курами. Нашими предыдущими исследованиями на самках перепелов породы фараон показано изменение с возрастом морфологических показателей яиц: снижалась плотность яиц, толщина скорлупы, индекс формы, однако соотношение желтка и белка значимо не менялось. При этом наблюдались различия и в эмбриональном развитии потом- ства: увеличивалась потеря массы яиц в процессе инкубации, задерживалось использование питательных веществ белка эмбрионами, снижался вывод перепелят за счет увеличения количества неоплодотворенных яиц с 3,5 до $23,8 \%$ [5].

Известно, что с возрастом матерей меняется выработка эмбрионами метаболического тепла: эмбрионы, развивающиеся в яйцах от старших родителей, производили больше тепла с 16 дня инкубации, чем эмбрионы из яиц молодого стада [6]. Аналогичная закономерность наблюдается и у эмбрионов от кур мясного направления продуктивности по 


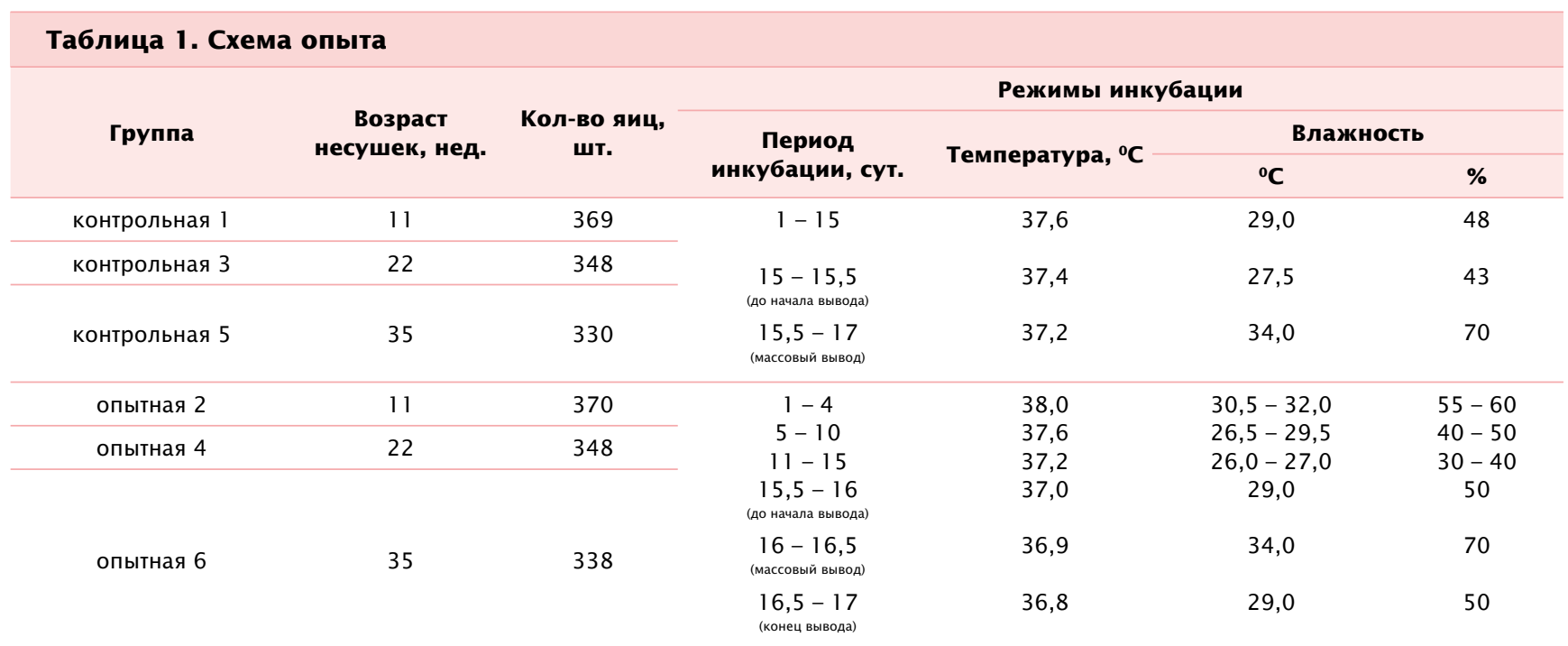

Таблица 2. Морфологические показатели яиц перепелов разного возраста

\begin{tabular}{lccc}
\hline \multirow{2}{*}{\multicolumn{1}{c}{ Показатель }} & \multicolumn{3}{c}{ Возраст птицы, нед. } \\
\cline { 2 - 4 } & $\mathbf{1 1}$ & $\mathbf{2 2}$ & $\mathbf{3 5}$ \\
\hline Масса яиц, г & $14,75 \pm 0,41$ & $14,26 \pm 0,16$ & $14,39 \pm 0,46$ \\
\hline Масса к массе яйца, \%: & & & \\
\hline белок & $62,88 \pm 0,82$ & $61,11 \pm 0,76$ & $61,13 \pm 0,87$ \\
желток & $28,94 \pm 0,69$ & $30,77 \pm 0,69$ & $30,32 \pm 0,72$ \\
скорлупа & $7,60 \pm 0,19$ & $8,07 \pm 0,14$ & $8,56 \pm 0,44$ \\
\hline Толщина скорлупы, мкм & $208 \pm 3,80^{\text {a }}$ & $196 \pm 4,25$ & $205 \pm 5,09$ \\
\hline Пористость скорлупы, шт./см² & $100,67 \pm 4,94^{\text {aаa }}$ & $73,17 \pm 2,96^{\text {bb }}$ & $111,47 \pm 5,77$ \\
\hline
\end{tabular}

Прим.: Различия были достоверны между возрастами: a, aаa -11 и 22 нед.; b, bb -22 и 35 нед. ( $\mathrm{p}<0,05$ и $\mathrm{p}<0,001$ соответственно).

сравнению с яичными [7]. В связи с этим яйца от кур старше 40 недель, а также от кур мясного направления продуктивности рекомендуется инкубировать с использованием дифференцированного по температуре и влажности режима [8].

На перепелах мясного направления продуктивности таких исследований не проводилось, поэтому целью настоящего исследования являлось сравнение стабильного и дифференцированного режимов инкубации яиц перепелок разного возраста породы радонежские, относящейся к мясному типу.

Материал и методика исследований. Опыты проводили в отделе инкубации и экспери- ментальном инкубатории отдела инкубации ФНЦ «ВНИТИП» РАН на инкубационных яйцах перепелок породы радонежские от несушек 11-, 22- и 35-недельного возраста. Методом аналогов по массе было сформировано 6 групп инкубационных яиц со сроком хранения не более 3 дней. Схема опыта представлена в табл. 1.

Контрольные и опытные группы яиц были сформированы от несушек трех возрастов следующим образом: 1 и 2 группы - возраст несушек 11 недель; 3 и 4 группы - 22 недели; 5 и 6 группы - 35 недель.

Контрольные группы яиц были проинкубированы по рекомендованному стабильному ре- жиму инкубации для перепелиных яиц [8]. Опытные группы яиц были проинкубированы по новому режиму инкубации, разработанному исходя из литературных данных и предварительных исследований.

Инкубацию яиц всех групп проводили в аналогичных инкубационных шкафах фирмы «Стимул Груп». Температура регистрировалась по контрольным термометрам и по датчикам, установленным в лотках около яиц. Морфологический и биохимический анализ яиц проводили согласно методическим рекомендациям [9].

Результаты исследований обрабатывали методом вариационной статистики с использование программы Microsoft Excel.

Результаты исследований и их обсуждение. В табл. 2 представлены основные морфологические признаки яиц перепелок в изучаемых возрастах. Ни масса яиц, ни относительные массы их составных частей - белка, желтка и скорлупы - не изменялись с возрастом матерей. Толщина скорлупы была самой низкой у перепелок 22-недельного возраста, достоверно отличаясь от тако- 
Таблица 3. Потеря массы яиц, \%

\begin{tabular}{|c|c|c|c|c|c|c|}
\hline \multirow{3}{*}{$\begin{array}{c}\text { Сутки } \\
\text { инкубации }\end{array}$} & \multicolumn{6}{|c|}{ Возраст матерей, нед./группа } \\
\hline & \multicolumn{2}{|c|}{11} & \multicolumn{2}{|c|}{22} & \multicolumn{2}{|c|}{35} \\
\hline & $1 к$ & 20 & Зк & 40 & $5 \kappa$ & 60 \\
\hline 6 & $4,57 \pm 0,11$ aаa & $4,34 \pm 0,10$ aаa & $3,83 \pm 0,12^{\mathrm{bbb}}$ & $3,55 \pm 0,17^{\mathrm{bbb}}$ & $4,55 \pm 0,12$ & $4,64 \pm 0,13$ \\
\hline 12 & $6,48 \pm 0,15$ & $6,16 \pm 0,14$ & $6,40 \pm 0,13$ & $6,31 \pm 0,16$ & $6,38 \pm 0,17$ & $6,66 \pm 0,19^{c}$ \\
\hline 15 & $9,26 \pm 0,24^{* * *}$ & $8,45 \pm 0,19$ a & $9,78 \pm 0,29$ & $9,35 \pm 0,29^{b}$ & $9,24 \pm 0,26$ & $9,49 \pm 0,28^{c c}$ \\
\hline
\end{tabular}

Прим.: Здесь и далее: а, аa, ааa - различия достоверны между возрастами 11 и 22 нед.; b, ьb, ььb - между возрастами 22 и 35 нед.; с, сс, сс - между возрастами 11 и 35 нед. (р<0,05; 0,01; 0,001 соответственно), при сравнении с соответствующей опытной либо контрольной группой. *,**,*** - различия достоверны между опытной и контрольной группой одного возраста (p<0,05; 0,01; 0,001 соответственно).

\section{Таблица 4. Показатели развития перепелов на 12,5 сутки инкубации}

\begin{tabular}{|c|c|c|c|c|c|c|}
\hline \multirow{3}{*}{$\begin{array}{c}\text { Отн. масса, \% от массы } \\
\text { яйца }\end{array}$} & \multicolumn{6}{|c|}{ Возраст матерей, нед./группа } \\
\hline & \multicolumn{2}{|c|}{11} & \multicolumn{2}{|c|}{22} & \multicolumn{2}{|c|}{35} \\
\hline & 1 к & 20 & Зк & 40 & $5 \kappa$ & 60 \\
\hline эмбрион & $\begin{array}{c}29,46 \\
\pm 0,27^{\text {aaa }^{*}}\end{array}$ & $\begin{array}{l}32,36 \\
\pm 1,11^{\text {aa }}\end{array}$ & $\begin{array}{l}27,03 \\
\pm 0,49^{b}\end{array}$ & $\begin{array}{r}27,31 \\
\pm 0,92^{\mathrm{bb}}\end{array}$ & $\begin{array}{l}29,13 \\
\pm 0,67^{\text {** }}\end{array}$ & $\begin{array}{l}32,92 \\
\pm 0,87\end{array}$ \\
\hline желток & $\begin{array}{l}23,11 \\
\pm 0,84\end{array}$ & $\begin{array}{l}21,61 \\
\pm 1,61\end{array}$ & $\begin{array}{l}23,48 \\
\pm 1,03\end{array}$ & $\begin{array}{l}23,16 \\
\pm 1,68\end{array}$ & $\begin{array}{l}23,79 \\
\pm 2,16\end{array}$ & $\begin{array}{l}21,51 \\
\pm 0,71\end{array}$ \\
\hline белок & $\begin{array}{c}3,42 \\
\pm 0,92\end{array}$ & $\begin{array}{c}4,55 \\
\pm 1,01\end{array}$ & $\begin{array}{c}2,79 \\
\pm 0,87\end{array}$ & $\begin{array}{c}3,58 \\
\pm 1,12\end{array}$ & $\begin{array}{c}3,60 \\
\pm 0,88^{*}\end{array}$ & $\begin{array}{r}1,57 \\
\pm 0,39\end{array}$ \\
\hline
\end{tabular}

вой у перепелок 11-недельного возраста ( $<<0,05)$; при этом наблюдалось значимое снижение пористости скорлупы яиц у перепелок 22-недельного возраста по сравнению с перепелками 11- и 35-недельного возрастов $(\mathrm{p}<0,001)$.

Потеря массы яиц может косвенно указывать не только на отклонения физических параметров инкубации - температуры и влажности, но и на метаболические особенности развивающихся эмбрионов.

Как видно из данных, представленных в табл. 3, на 6 сутки инкубации наблюдались самые низкие потери массы яиц у перепелов среднего возраста, по сравнению с двумя другими возрастами $(p<0,001)$, как в опытных, так и в контрольных группах. Вероятно, это было связано со значительно более низкой пористостью скорлупы яиц. На 12 и 15 сутки инкубации потеря массы яиц в опытных группах увеличивалась с возрастом матерей. Так, на 12 сутки инкубации потеря массы была достоверно выше у 35-недельных перепелок по сравнению с 11-недельными $(p<0,05)$, а к 15 суткам различия были достоверны между перепелами всех возрастов ( $p<0,05-$ 0,01). Различия по признаку потери массы между разными режимами инкубации наблюдались только у яиц от перепелок молодого возраста: в опытной группе 2 она была достоверно ниже, чем в контрольной группе $1(p<0,01)$.

Относительная масса эмбриона и использование им компонентов яйца (желтка и белка) являются показателями, определяющими интенсивность их развития. Данные по этим показателям приведены в табл. 4.

В нашем исследовании относительная масса эмбриона была выше в группах с дифференцированным режимом инкубации, по сравнению с контрольными группами, в молодом и старшем возрасте $(p<0,05-0,01)$. Эмбрионы от перепелок среднего возраста имели наиболее низкую относительную массу тела по сравнению с другими возрастами и в контрольной, и в опытной группах ( $p<0,05-0,001)$. По использованию желтка достоверных различий не наблюдалось. Белок максимально был использован в опытной группе перепелок старшего возраста, достоверно отличаясь как от контрольной группы в этом же возрасте, так и от опытной группы молодых перепелок $(p<0,05)$.

В табл. 5 представлены результаты инкубации яиц. С возрастом кур выводимость яиц имела тенденцию к повышению, независимо от режима инкубации. В опытных группах выводимость также была выше, чем в контрольных, на 2,6-9,3\%, разница была достоверной у молодых перепелов $(p<0,01)$. Оплодотворенность яиц снижалась с возрастом перепе- 
Таблица 5. Результаты инкубации яиц перепелов

\begin{tabular}{|c|c|c|c|c|c|c|}
\hline \multirow{3}{*}{ Показатель } & \multicolumn{6}{|c|}{ Возраст матерей, нед./группа } \\
\hline & \multicolumn{2}{|c|}{11} & \multicolumn{2}{|c|}{22} & \multicolumn{2}{|c|}{35} \\
\hline & $1 \mathbf{к}$ & 20 & $\mathbf{3 к}$ & 40 & $5 \kappa$ & 60 \\
\hline Оплодотворенность яиц, \% & 86,99 & 86,49 & $85,63^{b}$ & 84,77 & $79,39 c$ & $81,95^{c}$ \\
\hline Выводимость яиц, \% & $79,13^{\text {w*t }}$ & 88,44 & 79,53 & 82,37 & 81,68 & 85,56 \\
\hline Вывод перепелят, \% & $68,83^{*}$ & $76,49^{a}$ & 68,10 & 69,83 & $64,85^{*}$ & $70,12^{c}$ \\
\hline $\begin{array}{l}\text { Отходы инкубации, \%: } \\
\text { ранняя гибель } \\
\text { кровяное кольцо } \\
\text { замершие } \\
\text { задохлики }\end{array}$ & $\begin{array}{l}3,25 \\
3,52 \\
1,90 \\
5,42\end{array}$ & $\begin{array}{l}1,62 \\
2,43 \\
1,89 \\
4,05\end{array}$ & $\begin{array}{l}1,72 \\
2,01 \\
3,45^{\star} \\
5,46\end{array}$ & $\begin{array}{l}2,87 \\
2,01 \\
1,72 \\
4,31\end{array}$ & $\begin{array}{l}2,42 \\
3,03 \\
2,42 \\
3,03\end{array}$ & $\begin{array}{l}2,07 \\
2,37 \\
2,07 \\
3,85\end{array}$ \\
\hline $\begin{array}{l}\text { Кондиционные перепелята, \%: } \\
\text { I кат. } \\
\text { II кат. }\end{array}$ & $\begin{array}{c}96,85 \\
3,15\end{array}$ & $\begin{array}{c}96,82 \\
3,18\end{array}$ & $\begin{array}{c}92,83 \\
7,17\end{array}$ & $\begin{array}{c}96,71 \\
3,29\end{array}$ & $\begin{array}{c}96,73 \\
3,27\end{array}$ & $\begin{array}{c}97,47 \\
2,53\end{array}$ \\
\hline Некондиционные перепелята, \% & 4,07 & 3,78 & 4,89 & 3,45 & 3,33 & 1,48 \\
\hline Масса перепелят, г & $\begin{array}{c}9,71 \\
\pm 0,19^{\text {aa }}\end{array}$ & $\begin{array}{c}9,59 \\
\pm 0,15^{a}\end{array}$ & $\begin{array}{c}8,84 \\
\pm 0,11^{\mathrm{bbb}}\end{array}$ & $\begin{array}{c}9,15 \\
\pm 0,13\end{array}$ & $\begin{array}{c}9,88 \\
\pm 0,12\end{array}$ & $\begin{array}{r}9,45 \\
\pm 0,28\end{array}$ \\
\hline $\begin{array}{l}\text { Масса перепелят, } \\
\text { \% от массы яйца, }\end{array}$ & $\begin{array}{l}68,87 \\
\pm 1,46\end{array}$ & $\begin{array}{l}67,52 \\
\pm 0,92\end{array}$ & $\begin{array}{c}66,07 \\
\pm 0,64^{\text {bb }}\end{array}$ & $\begin{array}{l}67,38 \\
\pm 1,11\end{array}$ & $\begin{array}{l}70,34 \\
\pm 0,88\end{array}$ & $\begin{array}{l}66,86 \\
\pm 1,78\end{array}$ \\
\hline Масса тела, \% от массы яйца & $\begin{array}{l}63,31 \\
\pm 1,12\end{array}$ & $\begin{array}{l}63,20 \\
\pm 0,98\end{array}$ & $\begin{array}{c}61,75 \\
\pm 0,48^{\mathrm{b}}\end{array}$ & $\begin{array}{c}63,50 \\
\pm 1,38^{\mathrm{b}}\end{array}$ & $\begin{array}{l}64,68 \\
\pm 0,83\end{array}$ & $\begin{array}{l}62,81 \\
\pm 1,63\end{array}$ \\
\hline
\end{tabular}

лок, разница была достоверной между перепелками 22- и 35-недельного возраста в контрольных группах $(p<0,05)$ и перепелками 11 - и 35-недельного возраста как в контрольных $(p<0,01)$, так и в опытных группах $(p<0,05)$. Вывод перепелят также снижался с возрастом перепелок, с достоверной разницей между 11-и 22-недельными и 11-и 35-недельными матерями $(p<0,05)$. Вывод перепелят из яиц от 11-и 35-недельных матерей был выше в опытных группах по сравнению с контрольными (p<0,05). Статистически значимые отличия по времени гибели эмбрионов наблюдались только у перепелов 22-недельного возраста в зависимости от режима инкубации: в контрольной группе было выше количество замерших эмбрионов по сравнению с опытной $(p<0,05)$.

Живая масса суточных перепелят от матерей 22-недельного возраста была достоверно более низ- кой по сравнению с перепелятами от 11 -недельных $(p<0,0-0,01)$ и 35-недельных матерей $(p<0,001)$. Относительная масса перепелят (в \% от массы яйца) была также более низкой у птенцов от матерей 22-недельного возраста в контрольной группе по сравнению с той же группой от 35-недельной птицы $(p<0,01)$. Зависимости абсолютной и относительной массы перепелят от режима инкубации не наблюдалось.

Заключение. По результатам исследований можно сделать следующие выводы:

1. Возраст самок перепелов не оказывал значительного влияния на морфологические признаки инкубационных яиц. Наблюдалось лишь снижение толщины и пористости скорлупы яиц у перепелок 22-недельного возраста. Вероятно, это повлияло на увеличение потери массы яйцами от перепелок этого возраста до 6-су- точного срока инкубации. К 15 суткам инкубации потеря массы яиц в опытных группах статистически значимо увеличивалась с возрастом матерей.

2. Различия в потере массы яиц наблюдались между разными режимами инкубации у яиц от перепелок молодого возраста: в опытной группе она была достоверно ниже $(p<0,01)$.

3. Относительная масса тела 12,5-суточных эмбрионов была наиболее низкой у перепелок среднего возраста по сравнению с другими возрастами ( $<<0,05-0,001)$.

4. Относительная масса эмбрионов была выше в группах с дифференцированным режимом инкубации, по сравнению с контрольными группами, в молодом и старшем возрасте $(p<0,05$ и $p<0,01$ соответственно).

5. С возрастом перепелок снижались оплодотворенность 
яиц и вывод перепелят, тогда как выводимость яиц имела самые низкие показатели у перепелок 22-недельного возраста.

6. В группах с дифференцированным режимом инкубации выводимость была выше, чем в контрольных группах, на 2,6-9,3\%, разница была достоверной у молодых перепелов $(p<0,01)$.

7. Вывод перепелят из яиц 11-и 35-недельных перепелов был выше в группах с дифрференцированным режимом инкубации по сравнению с контрольными группами $(p<0,05)$.

\section{Литература}

1. Ramli M.B, Wahab M.S., Zain B.A. [et al.] Effect of incubation temperature on IKTA's quail breed with new rolling mechanism system // J. Mechan. Engin. - 2017. - V. 10. - P. 78-88.

2. Iqbal J. Effects of egg size (weight) and age on hatching performance and chick quality of broiler breeder / J. Iqbal, S.H. Khan, N. Mukhtar, T. Ahmed, R.A. Pasha // J. Appl. Anim. Res. 2016. - V 44. - P. 54-64.
3. Santos T.C. Influence of European quail breeders age on egg quality, incubation, fertility and progeny performance / T.C. Santos, A.E. Murakami, C.A.L. Oliveira, G.V. Moraes, C. Stefanello, T.V. Carneiro, C.C.G. Feitosa, I.N. Kaneko // Rev. Bras. Cienc. Avic. 2015. - V. 17, No 1. - P. 49-56.

4. Долгорукова А.М., Журавлев И.В. Особенности эмбрионального развития мясных кур в зависимости от массы яиц и соотношения в них желтка и белка // Инновационные разработки и их освоение в промышленном птицеводстве: Мат. XVII Междунар. конф. ВНАП. - Сергиев Посад, 2012. C. 55-58.

5. Гупало И.М. Влияние возраста перепелок на инкубационные качества яиц и эмбриональное развитие / И.М. Гупало, А.А. Зотов, А.М. Долгорукова, Р.В. Данилов, М.С. Тишенкова, Т.А. Мелехина // Птицеводство. 2020. -№9. - С. 63-66.

6. Nangsuay A. Energy utilization and heat production of embryos from eggs originating from young and old broiler breeder flocks / A. Nangsuay, R. Meijerhof, Y. Ruangpanit, B. Kemp, H. van den Brand // Poult. Sci. - 2013. - V. 92, No 2. - P. 474-482.
7. Nangsuay A. Differences in egg nutrient availability, development, and nutrient metabolism of broiler and layer embryos / A. Nangsuay, R. Molenaar, R. Meijerhof, I. van den Anker, M.J.W. Heetkamp, B. Kemp, H. van den Brand // Poult. Sci. - 2015. - V. 94, No 3. - P. 415-423.

8. Технология инкубации яиц сельскохозяйственной птицы. / В.И. Фисинин, Л.Ф. Дядичкина, Ю.С. Голдин [и др.]. Сергиев Посад: ВНИТИП, 2016. - 90 с.

9. Биологический контроль при инкубации яиц сельскохозяйственной птицы / Л.Ф. Дядичкина, Н.С. Позднякова, Т.А. Мелехина [и др.]. - Сергиев Посад: ВНИТИП, 2014. - 171 с.

\section{Для контакта с авторами:}

\section{Долгорукова}

Анна Михайловна

E-mail: anna.dolg@mail.ru

Зотов Александр Анатольевич

E-mail: inkub@vnitip.ru

Тишенкова Мария Сергеевна

E-mail: mmihalyowa@yandex.ru

Данилов Роман Владимирович

E-mail: rvdanilov@mail.ru

Мелёхина

Татьяна Александровна

E-mail: inkub1@vnitip.ru

\title{
The Effects of Different Incubation Regimes on the Embryonic Development and Incubation Efficiency in Eggs of Radonezhskiye Quail Breed Laid at Different Hen Ages
}

Dolgorukova A.M., Zotov A.A., Tishenkova M.S., Danilov R.V., Melekhina T.A.

\author{
Federal Scientific Center "All-Russian Research and Technological Institute of Poultry" \\ of Russian Academy of Sciences
}

\begin{abstract}
Summary: Embryonic development and efficiency of incubation in eggs of newly selected Russian meat-type quail breed Radonezhskiye laid at different hen ages (1 1, 22 and 35 weeks of age) with two different incubation regimes were comparatively studied. It was found that egg fertility and hatch of poults decreased with the hens' age while egg hatchability was the lowest at 22 weeks of hens' age. In the treatments with differentiated incubation regime egg hatchability was higher in compare to control treatments with constant incubation regime by 2.6-9.3\%; the difference between the regimes was significant $(p<0.01)$ at 11 weeks of hens' age. Hatch of poults at hens' ages 11 and 35 weeks with the differentiated incubation regime was significantly higher in compare to the respective control treatments $(p<0.05)$.
\end{abstract}

Keywords: Radonezhskiye quail breed, quality of eggs for incubation, hens' age, temperature and humidity during incubation, egg fertility, egg hatchability, hatch of poults. 